\title{
El Sol Blanco en la Ladera. Análisis preliminar de las pinturas rupestres de el Damie, San Juan Solís, San Agustín Tlaxiaca, Hidalgo.
}

\section{The White Sun on the Hillside. Preliminary analysis of the cave paintings in el Damie, San Juan Solís, San Agustín Tlaxiaca, Hidalgo. \\ Oscar Omaña Nájera ${ }^{a}$}

\begin{abstract}
:
The municipality of San Agustín Tlaxiaca, due to the few investigations carried out in it, has been considered a territory of passage during Mesoamerican times. Until the 90s it was considered that the municipality lacked material remains that would confirm the presence of its former inhabitants., For this reason, the panels of cave paintings located in the community of San Juan Solís, the Damie and the Huarache, turn out to be two important windows for the study of the inhabitants of the area in the Postclassic, the understanding of their way of subsistence and their settlements. These testimonies in the rocky walls are an approach to the thought of the groups who They painted these sites, in addition to the fact that for the reasons reflected, the cultural affiliation of their authors can be tentatively determined. Therefore, the studies carried out in these sites are of great relevance, since they broaden the panorama that we have about the rituals socials concerns, which were painted for posterity, in a region where this type of research is lacking.
\end{abstract}

Keywords:

Cave paintings, astromorphic motifs, Otomi, meteomorphic motifs, Postclasic.

\section{Resumen:}

El municipio de San Agustín Tlaxiaca, debido a las pocas investigaciones realizadas en el municipio, ha sido considerado como un territorio de paso durante la época mesoamericana., Hasta los años 90's se consideraba que el municipio carecía de restos materiales que confirmaran la presencia de sus antiguos pobladores., Por esta razón los conjuntos de pinturas rupestres localizados en la comunidad de San Juan Solís, el Damie y el Huarache, resultan ser dos importantes ventanas para el estudio de los pobladores de la zona en el Postclásico, el entendimiento de su modo de subsistencia y sus asentamientos., Estos testimonios en las paredes rocosas, son un acercamiento al pensamiento de los grupos quienes pintaron estos sitios, además de que por los motivos plasmados se puede determinar tentativamente la filiación cultural de sus autores., Por ello los estudios que se realicen en estos sitios son de gran relevancia, puesto que amplían el panorama que tenemos sobre las inquietudes, rituales y sociales, las cuales quedaron pintadas para la posteridad, en una región donde se carecen de este tipo de investigaciones.

\section{Palabras Clave:}

Pinturas rupestres, motivos astromorfos, Otomíes, motivos meteomorfos, Posclásico.

\section{Introducción}

Distribuido entre las muchas barrancas, cerros, montañas, cuevas, laderas o veredas, por todo el territorio del Estado de Hidalgo, se cuenta con impresionante y gran acervo de Gráfica Rupestre, entendido "como el conjunto de representaciones realizadas sobre el soporte rocoso, con diversas técnicas, pintura, grabado, impresiones, imágenes en negativo, esculturas o relieve" (Cruz, 2004)., Se pueden observar desde petrograbados, asociados con las zonas arqueológicas., El Cerro de la Malinche en Tula en un ejemplo de esto o los sitios de Xihuingo en Tepeapulco y Pañhu en Tecozautla donde los grabados forman parte de los atractivos de las zonas., Por su parte las pinturas rupestres se encuentran en casi todas las regiones que componen el estado, desde el Valle de Tulancingo hasta el Mezquital, y los municipios con los más ricos acervos

Autor de Correspondencia, Escuela Nacional de Antropología e Historia, https://orcid.org/0000-0002-9673-6420, Email: osaymh17@hotmail.com 
Huichapan, Alfajayucan y Tecozautla., Estas pinturas cuentan con los más diversos motivos, colores, temporalidades, y significados., Aunque estas en un primer momento puedan parecer inconexas, una cantidad considerable de estos sitios con pinturas rupestres, debido a sus características similares en cuanto a la tonalidad y motivos representados, han sido incluidas dentro de una misma familia., Investigadores como Roberto Martínez, señalan que miembros de esta familia se han encontrado en el Estado de México, Querétaro y principalmente en Hidalgo, de ahí que se les denomine como la Familia del Estado de Hidalgo de pinturas rupestres., Coincidiendo para todas ellas que se localizaron en áreas de ocupación de grupos con filiación Otomí.,

San Agustín Tlaxiaca, uno de los 84 municipios que componen al Estado de Hidalgo, no se relaciona para nada al municipio de San Agustín Tlaxiaca con este tipo de representaciones, al grado que no figura dentro del mapa estatal realizado por la Secretaría de Cultura de Hidalgo, donde se ubican los municipios y sitios con pinturas rupestres o petrograbados., Sin embargo, el municipio si cuenta con 2 conjuntos de pinturas rupestres de manufactura prehispánica, el Damie y el Huarache, conjuntos separados por unos 3 kilómetros de recorrido, por la barranca en donde se localizan., Ambos sitios, de acuerdo a algunas características y parámetros que componen a las pinturas rupestres consideradas dentro de la Familia del Estado de Hidalgo, pueden ser candidatos a considerarse como parte de esta familia.

Por lo anterior, el objetivo del presente es un análisis preliminar de las pinturas rupestres que se localizan en el primero de estos sitios el Damie., Para sustentar su posible pertenencia a los sitios con pinturas rupestres de la Familia del Estado de Hidalgo., Mediante una comparación de otros sitios de pinturas rupestres identificados con la misma, ubicados entre el Estado de México e Hidalgo., Presentando sus similitudes y características que lo incorporarían dentro de esa familia., Además de la realización de recorridos de superficie y de prospección para hacer un acopio de materiales, para después estudiarlos y compararlos con otros materiales que se han encontrado en la región o similares, el recorrido de superficie también se hace con la finalidad de poder fotografiar, registrar y medir los motivos en el sitio del Damie., Investigar que antecedentes de estudios se tienen en la zona, aunado a lo anterior, se revisarán las fuentes etnohistóricas donde se describen a los ocupantes de esta región y zonas aledañas, para el periodo Posclásico., Sin dejar de lado la investigación y recopilación de otros hallazgos arqueológicos que se hayan dado en el pasado, esto mediante métodos etnográficos como cuestionarios y entrevistas a la población de San Juan Solís, en conjunto a las búsquedas dentro de los archivos del Centro INAH Hidalgo., Para que con todo ello se pueda determinar la autenticidad de las pinturas del sitio y en base a la terminología empleada se les pueda dar una primera interpretación tentativa a los motivos., Finalmente en base a la evidencia reunida, se podrá proponer la posible filiación cultural de sus autores.

\section{DESARROLLO}

Para comenzar es preciso describir el área donde se encuentra el Damie., Las pinturas rupestres son pertenecientes al Barrio de la Gloria, de la localidad de San Juan Solís, municipio de San Agustín Tlaxiaca., Como una referencia más puntual para localizarlas tenemos su proximidad con la carretera PachucaActopan, las pinturas del Huarache están a menos de un kilómetro del puente después del retorno que conduce a San Juan Solís., El sitio del Damie se haya frente a una presa, justo en medio de las laderas de una barranca, por la cual antes pasaba el cauce de un río, del que solo restan pozas o estanques y pequeños escurrimientos que abastecen ocasionalmente a la presa., El camino para llegar al sitio en auto cruza por un antiguo canal de riego agrícola, de acuerdo con los cronistas del pueblo y fotografías conservadas, este se habría construido en los primeros años de la década de los 20's del siglo pasado, justo después de que terminara la Revolución., En cuanto al origen del nombre "El Damie", los habitantes de la comunidad de San Juan Solís, concuerdan en que la palabra en cuestión puede ser de origen otomí, pero 
que con el paso del tiempo, el vocablo original se deformó y terminó siendo adecuado como el damie., Aunado a lo anterior tenemos que uno de estos estanques que se forman en las partes bajas de la barranca, lleva el mismo nombre., Este cuerpo de agua se localiza justo en medio de ambos sitios, y también nombra al paso de esa zona., El nombre del estanque debido a su cercanía con las pinturas y a la carencia de otros lugares reconocidos dentro de la población que cuenten con nombre como para ser usados como referencia, le fue dado al sitio de las pinturas rupestres., La ladera donde se encuentran las pinturas, presenta algunos abrigos rocosos o cuevas a lo largo, muchas de ellas ahora están ocupadas con serpientes, por lo que para su visita fue necesario hacerlo en horarios anteriores a las 10 de la mañana., Una gran cantidad de estas cuevas, son lo suficientemente grandes como para que una persona de 1.70 metros de alto pueda entrar sin problemas, no siendo tan profundas, variando sus medidas en este rubro de los 30 centímetros a 5 metros., El sitio del Damie se compone de dos cuevas, separadas por una pared rocosa con oquedades en ella que permiten una vista total de la cueva a su lado., En la primera de estas, ubicada al lado izquierdo, se localizan 2 paneles con pinturas rupestres, los motivos con los que cuenta este primer grupo son astronómicos., La segunda cueva de mayor altura y profundidad, posee 5 motivos separados 3 de ellos forman un panel, mientras que el cuarto fue pintado en el techo de la cueva, separado del resto por unos metros., Los signos encontrados, entran en las categorías de formas geométricas, astromorfas y abstractas, conceptos que serán desglosados posteriormente.

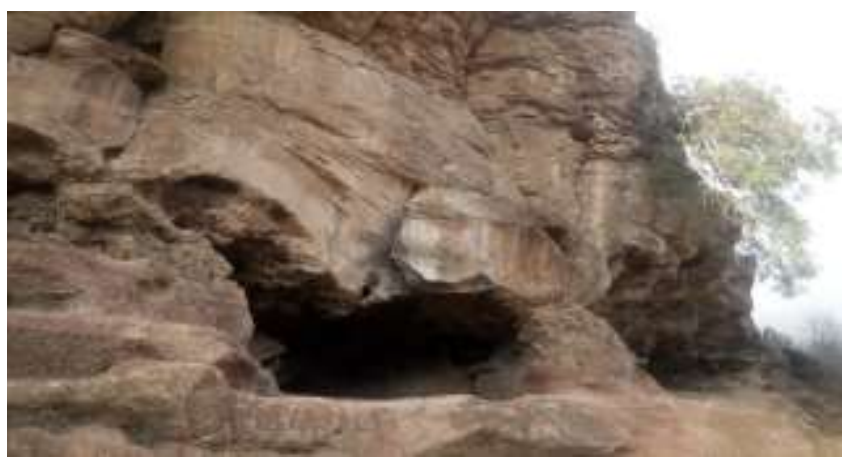

Imagen 1. Las cuevas que component al sitio del Damie.
Existe una terrible problemática al analizar el sitio de El Damie, ya que no existen estudios similares para el municipio donde se encuentra, los más cercanos análisis que se han llevado a cabo, se enfocaron en sitios del Valle del Mezquital., Por ello no se pretende dar respuestas absolutas en el presente, se trata más bien de un primer acercamiento al sitio en lo referente a la edad, afiliación cultural o significado de las pinturas, campos muy complejos y difíciles de tratar, debido a las múltiples teorías que pueden surgir, las diferentes temáticas que abarcan, la dificultad de datarlas con métodos absolutos o la ambigüedad., Aclarando que todo lo expuesto que no tenga un sustento material, se debe de considerar como mera especulación procedente de una teoría o hipótesis argumentada., Pero se ha decidido llevar a cabo este análisis, para que en el futuro se puedan realizar más trabajos en el sitio, tomando este como punto de referencia, ya sea para usar la información expuesta o para criticarla, por lo que la opinión expuesta se encuentra condicionada con la información, teorías y técnicas de investigación con las cuales se dispone en el momento de realización del mismo., Esperando que para las siguientes investigaciones en la región, lo expuesto pueda modificarse 0 enriquecerse con los nuevos trabajos o la evidencia que se vaya presentando., Afortunadamente se cuenta con la suficiente evidencia para dar una sólida argumentación que nos acerque a una interpretación primeriza de las pinturas, así como para iniciar con la identificación de la filiación de sus ocupantes. La principal problemática con el Arte Rupestre es que "el arte no sabe hablar por sí mismo" (Montes, 2012), para poder entenderlo es necesario comprender la intención de quienes lo hicieron en tres niveles "psicológico, sociológico e iconográfico-ideológico" (Montes, 2012)., Para el caso del presente, me centraré en los últimos aspectos listados, ya que estos resultan ser los campos, para el cual contamos con mayor evidencia, teorías e información que nos permitiría comprenderlos. Hablar del nivel sociológico es hablar acerca de la sociedad por las que fueron realizadas las pinturas, por lo que la interrogante de la filiación cultural de las pinturas 
rupestres de El Damie será lo primero a analizar en el presente., No se ha podido determinar a los autores de este sitio, por el otro lado, si se puede afiliar, al menos de forma tentativa por ahora, con los grupos Otomíes, creadores de las pinturas rupestres de la Familia del Estado de Hidalgo., Esto se debe principalmente a los motivos de las pinturas, el color usado en los pigmentos y el área donde se encuentran ubicados., Para esto es necesario brindar un breve recorrido por la territorialidad de los Otomíes en el Estado de Hidalgo, apoyándonos para ello en las fuentes etnohistóricas y los estudios realizados en ellas., Este recorrido sin embargo, no abarcará toda la antigüedad de los grupos Otomangues, porque como lo reconocen instancias con la calidad del INAH o el INALI, son la nación más antigua de Mesoamérica., Al grado de que el Instituto Nacional de Lenguas Indígenas ha ubicado tentativamente su origen, por medio de la glotocronología lingüística o el estudio de las palabras dentro una lengua, donde se determina cuáles de estos son originales y cuales se han adoptado de otras, para hace más de 6,500 años., Por lo cual solo se tratará su territorialidad en el Posclásico y en el área del Centro de México que corresponde al estado de Hidalgo y los estados colindantes., Que serían tanto la época donde los grupos Otomíes habitaron o circularon por la región donde se ubica el Damie y la región geográfica donde se encuentra el sitio., Como primer dato de esto tenemos que "previo al establecimiento Tolteca en Tula, existió el pueblo Otomí de Mahmeni" (Galicia y Sánchez, 2004)., Este habría sido un centro importante previo a la fundación de Jilotepec, (capital de los Otomíes después de la caída de Tula, localizado en el Estado de Querétaro), cercano a la zona de Tula, habitado principalmente por los grupos Otomíes., Posteriormente este centro sería absorbido por el estado Tolteca, ya que como se ha dicho, se encontraba en región cercana con la urbe Tolteca, por lo que habría quedado sojuzgado a la metrópoli., Posteriormente con la caída de Tula y más en específico con el colapso de la Frontera Agrícola que se produjo tras la caída del régimen Tolteca, a fines del Posclásico Temprano (900-1,200 d.c.)., Trajo como consecuencia que el área que comprende al actual
Estado de Hidalgo en los tiempos del Posclásico Tardío (1,200-1521 d.c.), "fuera la frontera cultural entre los grupos agricultores y nómadas" (Lerma et al., 2014)., Los Otomíes realizaron sus primeras migraciones del Posclásico Tardío para "el 1220 cuando se establecieron en la región de Xilotepec-Chiapan, después hacia Xaltocan" (Lorenzo y Vergara, 2015), en donde establecieron sus nuevas cabeceras, volviendo a ser independientes., Pero ante la falta de alimento, y la ausencia de un poder que regulara el paso de los nómadas del norte hacia el centro, los grupos Chichimecas buscaban llegar al Altiplano Central y tomar el control de las zonas agrícolas, donde habitaban los grupos Otomíes, por lo que "se produjeron una serie de migraciones y desplazamientos de población en el Centro y Norte de México" (Lorenzo y Vergara, 2015), uno de estos grandes desplazamientos fue el de los Chichimecas de Xólotl., Estos a su llegada y posterior colonización de la zona, formarían a la Chichimecatlalli que comprende a los actuales municipios de "Tula, Tizayuca, Mixquiahuala, Actopan, Zempoala y Tepeapulco" (Galicia y Sánchez, 2004)., Tenemos registros de que esta ocupación se hubiera dado para el siglo XIV más en específico el año de " 1398 cuando los Tepanecas desplazan a los Otomíes del territorio de la Teotlalpan hacia Metztitlán, Tutotepec y el Mezquital" (Lorenzo y Vergara, 2015), aquellos que se dirigieron al Mezquital se separarían de los otros y se autonombrarían como Ñhañhu traducido como "Quienes hablan por la nariz", este grupo dentro de los Otomíes es el que nos resulta más relevante, puesto que contrario a otros, como los de Tutotepec, no se caracterizarían por sus construcciones, como es el caso del Sitio de México Chiquito o la pirámide de Tutotepec cuyas bases aún se localizan debajo de la parroquia construida en el siglo $\mathrm{XVI}$, sino que se distinguen por el amplio acervo de gráfica rupestre que crearon, la cual da forma a la Familia del Estado de Hidalgo., López Callejas señala que en paralelo a los Ñhañhu, otros grupos filiación Otomí terminaron Ilegando hacia la Sierra Norte de Puebla e inclusive al área de Huayacocotla en Veracruz., El mismo autor hace hincapié que regiones como Pachuca, fueron y seguían estando habitadas mayoritariamente por 
Otomíes, para cuando los Mexicas dominaban el área en el Posclásico Tardío., Carmen Lorenzo Monterrubio, ha señalado que los grupos nómadas de Chichimecas recién llegados para mediados del Posclásico Tardío, estarían emparentados con los Pames, esto resulta importante puesto que el INALI reconoce que grupos identificados con Chichimecas como Pames o Jonaces, se encuentran emparentados lingüísticamente con los Otomíes, además de compartir cierta filiación histórica., Esta se debe al momento en que los grupos Chichimecas ocuparon y colonizaron las áreas Otomíes, se mesclaron con los habitantes, adquiriendo y compartiendo cosas como el lenguaje, además de otros conocimientos como las técnicas de agricultura., Con la información expuesta hasta el momento, tenemos que la zona donde se ubica el Damie, estaba circulada por áreas Ñhañhus y Otomíes, por lo que podemos suponer que los autores de estas pinturas podrían ser pertenecientes a estos grupos., Lo cual nos ayudaría mucho a comprender los motivos plasmados en el sitio, ya que de ser de filiación Otomí, en alguna de sus variantes, contamos con otros ejemplos de estudios realizados en cuanto a los símbolos del Arte Rupestre Otomí y sus significados., Pero antes de adelantarnos a esto, vayamos a ver que otra información tenemos con respecto a la ocupación de la zona., Ya que tanto pueden tratarse de grupos con filiación Otomí, como grupos Chichimecas con filiación igualmente Otomíes, y en ese caso la cantidad de estudios sobre ese tema es muy limitado.

En el año 1982 INAH fue avisado la existencia de unos 3 montículos en el Ejido de San Isidro Llano Largo, comunidad vecina y colindante con San Juan Solís, cercano al Cerro El Tequía (usado como punto de referencia para dividir tres comunidades, San Juan Solís, San Isidro e Izcuincuitlapilco), donde se hizo un trabajo de salvamento y rescate arqueológico en el lugar, debido a que se buscaba la autorización para que la zona pudiera ser demolida para ser usada convertida en milpas y lugar para el ganado, además de que igualmente se deseaba usar el material pétreo con fines de relleno, nivelación y para cimientos de casas que estaban construyéndose en San Juan Solís y San Isidro., Lo cual terminó sucediendo para el año siguiente, encontrando como piezas más sobresalientes una escultura antropomorfa en buenas condiciones y la cabeza de otra, así como otras piezas cerámicas, la mayoría de estas tepalcates, los cuales se siguen encontrando a lo largo de todo el Cerro del Tequía, además de silbatos y restos de figurillas, especialmente cuando se barbecha la tierra, en preparación para la siembra., Esto sin mencionar que tiempo después se identificarían otros 3 montículos de mayor tamaño frente a otra zona del cerro, estos no serían intervenidos de ninguna forma por el INAH., Los cuales corrieron con la misma suerte de ser demolidos, salvo uno de estos que se conserva en medio de un campo de cultivo, pero en muy malas condiciones, ya que fue usado como un bando de material.,

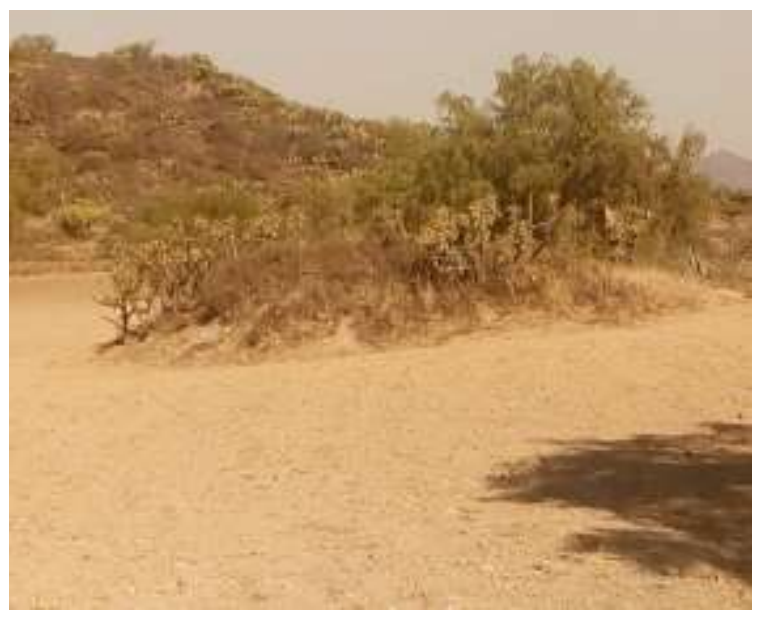

Imagen 2. Montículo del Tequia.

En cuanto a los materiales, rescatados durante el salvamento, fueron llevados al Centro INAH Hidalgo para su estudio, después de su análisis, se determinó que las esculturas se trataban de portaestandartes, y gracias a la cerámica se concluyó que su estilo era Tolteca o que poseía influencias de esta cultura., Aunado a lo anterior los investigadores del INAH le dijeron a la comunidad que el sitio, era un adoratorio de paso, explicándolo como un lugar construido en las cercanías de los caminos, como sitios de descanso seguros, además de cumplir con la función de templos de oración para el resguardo de los viajeros., Fuera de este reporte realizado por miembros de la comunidad al INAH, no se han realizado más llamadas a la institución, pero si se han seguido encontrado piezas, desde navajillas prismáticas de 
obsidiana, puntas de proyectil del mismo material, silbatos de barro, figurillas, orejeras de barro y huesos., Muchas de estas piezas debido al uso de maquinaria o herramientas salen fracturadas o con partes faltantes., Estos hallazgos se han dado como se mencionó previamente, en las épocas donde se preparan los cultivos, o en recorridos que se hacen por las barrancas y cerros de la región, sobre todo en las labores de pastoreo es donde más objetos de obsidiana se han encontrado, que como se ha mencionado antes, generalmente son navajillas o puntas de proyectil e inclusive algunos raspadores que pueden estar relacionados con la extracción del aguamiel de los magueyes, pero que al no tener estudios sobre la lítica de la región, estas posibilidades no pueden ser concretizadas del todo, salvo que la aparición de raspadores es muy aislada si se compara con la cantidad de navajillas prismáticas y puntas de proyectil., En dos colecciones de entre 10 y 20 piezas, que se me fueron mostradas, apenas había un raspador entre todos los objetos, siendo más común la aparición de puntas de proyectil.,

Se realizaron tres recorridos de prospección en el sitio, así como uno al sitio del Tequía, contando con guías locales., Mismos quienes fungieron como los informantes de los hallazgos de piezas que se han realizado desde hace varios años en la comunidad., En estos recorridos no se localizaron morteros, metates o herramientas para moler, por lo que al "no haber rastros de piedra de molienda, indicaría que los pigmentos no son preparados in situ o que los instrumentos fueron retirados o se trataban de materiales perecederos" (Martínez, 2002), añadiendo que de entre los diferentes guías, ninguno mencionó alguna vez hallado algún metate o escuchado de alguien que lo hubiera hecho., Lo anterior nos diría que no estamos ante un sitio de habitantes agricultores, o más bien que no se trataba de un sitio plenamente habitado, sino que más bien un asentamiento de cazadoresrecolectores, un punto de referencia de paso, o un lugar el cual pudo haber sido utilizado en temporadas específicas, como para la recolección de tunas y otros frutos que se dan en la zona, o visitado para ciertos eventos específicos., Sin embargo se debe contar al sitio del Tequía, que al tener construcciones de roca y de dimensiones mayores que al otro sitio cercano identificado como adoratorios de pasos, habría tenido una ocupación con agricultores que lo pudieran sostener., Pero se carecen de elementos que puedan relacionar al Damie o al Huarache con el Tequía de forma concreta, aunque sería muy irresponsable no considerar esta posibilidad ante la cercanía de estos sitios y que la variedad de obsidiana encontrada es la misma en los tres sitios, obsidiana dorada, probablemente perteneciente a la Sierra de las Navajas, como lo mencionan arqueólogos como Jannu Lira Alatorre, quien ha realizado investigaciones en el sitio, afirmando que "la obsidiana de la Sierra de las Navajas se distingue por sus tonalidades doradas" (Schonleber y Lira, 2007)., Por lo cual probablemente los sitios con pinturas rupestres, fueran usados en temporadas, celebraciones o tiempos específicos, por los habitantes del Tequía o de otras regiones que pasaran por la zona, (como lo atestigua la presencia de adoratorios de paso en la región), y para esto me sustentó con el tipo de materiales localizados en los recogidos, los testimonios de miembros de la comunidad, quienes han realizado hallazgos similares y los motivos presentes en la gráfica rupestre del Damie, como lo son los motivos astromorfos, que podría indicar que este fue un lugar de observación y la presencia de un arco, lo que tal vez se relacione con las actividades que se llevaban a cabo en las cercanías.

Para el caso de mis recorridos de superficie, se localizaron unas 15 navajillas prismáticas de obsidiana, estas siendo de obsidiana verde y dorada, color que coincide con "la materia prima extraída de las minas de obsidiana de la cercana Sierra de las Navajas" (Schonleber y Lira, 2007)., Así como 2 puntas de proyectil del mismo material y tonalidad., Estos objetos fueron localizados en el suelo cercano al Damie, en la Cueva donde se localizan las pinturas rupestres del Huarache y en el sendero que conecta a ambos sitios, por lo que se puede afirmar que se tratan de materiales asociados con los sitios., Al ser la mayoría de estos instrumentos de corte y herramientas relacionadas con la cacería como 
las puntas de proyectil, podríamos decir que los sitios del Damie y el Huarache, eran usados como puntos de cacería de temporada, debido a su cercanía con el cauce del río, y la abundancia relativa de mamíferos menores como liebres, conejos, o zorrillos y algunas aves, mismos que siguen presentes en la actualidad., Además este modo de subsistencia coincide con el que mantenían algunos grupos chichimecas con filiación Otomí, aunado a lo anterior, se encuentra presente una de las herramientas predilectas de estos grupos, las puntas de proyectil, mismas que les dieron su fama de haber sido diestros flechadores de pájaros, además de buenos arqueros, como lo relata la tradición oral en el municipio de San Bartolo Tutotepec, donde se sigue rememorando a los arqueros de esta cultura, quienes detuvieron a los Mexicas en sus intentos de conquista., Recordando que los sitios donde se encuentran las pinturas rupestres, desde la particular perspectiva de la arqueología del paisaje, como los abrigos rocosos, laderas o cuevas, pueden ser considerados como "elementos para la aproximación al paisaje simbólico, ya que es en su aspecto estratégico y territorial donde reside cierta parte de la importancia del sitio" (Berro, 2006)., Sin embargo, no se descarta la posibilidad, de que el sitio cumpliera con las funciones de cacería, para complementar de cierto modo la economía de subsistencia de algún centro cercano como el Tequía, además de la posibilidad de que resguardara el paso en esa zona de la barranca, ya que el otrora cauce de río, fue utilizado desde la fundación de la comunidad y sigue siendo utilizado como un camino, por lo que no podría resultar extraño pensar que su uso se remonte a esa época, lo cual también podría explicar la presencia del motivo del arco y las puntas de proyectil encontradas, como un indicador de los conflictos en la zona y el militarismo característico del periodo Posclásico.

Hemos revisitado los materiales arqueológicos localizados en la zona y en las cercanías, aunado a esto, igualmente se ha revisitado la territorialidad de la zona y los grupos que la habitaron, por consiguiente es momento de adentrarnos de lleno a las pinturas rupestres, siendo necesario dar primero algunos conceptos básicos y terminología para su estudio., Whitley considera que las pinturas rupestres, petrograbados y otras formas de expresión que componen al Arte Rupestre, pueden ser considerados como un verdadero arte, pues sus cualidades estéticas son de las pocas, que pese al paso de los milenios de la historia humana, han sido atemporales, y no solo eso, también tienen la característica de ser reconocibles por cualquier cultura en cualquier tiempo, como las formas de animales, humanos u otros motivos esquemáticos que plasmaron, ya que sus autores no las crearon con una función estética en mente, estos testimonios sobre la roca, se realizaron con una serie de motivos puntuales, diferentes para cada sitio, cultura o grupo que las hizo, pudiendo tener algún significado ritual, religioso, político, o de otra índole, por ello su estudio resulta fascinante., Ya se he dado una definición de la Gráfica Rupestre, pero considero necesario brindar conceptos complementarios para poder analizar únicamente a las pinturas rupestres, debido a que los términos usados por María Cruz Berrocal y otros autores, engloban a la totalidad de manifestaciones de este tipo de representaciones., Las pinturas, dentro del Arte Rupestre, han sido definidas por Julio Amador Bech, como aquellas que han sido realizadas mediante la aplicación de materia pictórica, sobre la superficie del soporte rocoso., Cruz Berrocal determinó como materia pictórica a los pigmentos de color, que proceden de la materia vegetal o mineral, así como el aglutinante o medio que tiene el objetivo de pegar las partículas pictóricas con el soporte rocoso.,

Será en el color donde encontremos otro argumento que sustenta mi teoría, que puede relacionar a El Damie con los grupos Otomíes, ya que en este sitio todas las pinturas rupestres fueron elaboradas con pigmentos que produjeron una tonalidad blanca., Este argumento se haya en el color blanco de la pintura, procedente de los pigmentos usados para realizarla., Esto es así, porque se conoce que entre los grupos de filiación Otomí se dio el "empleo preferencial del color blanco, posiblemente elaborado con un tipo de tierra blanca conocida como bok'o y aglutinantes" (Lerma et al., 2014), aunado a lo anterior, existen otras fuentes que nos informan sobre el 
origen del color blanco, ya que esta tonalidad también "se obtiene de roca caliza molida, disuelta en agua a manera de pasta o arcillas caolínicas del Meztitlán en Hidalgo" (Martínez, 2018), señorío controlado y habitado por miembros de la cultura Otomí., En cuanto al aglutinante igualmente se tiene evidencia y registros etnohistóricos, de los empleados en la región como el caso de "los Otomíes que usaban savia de maguey, nopal y grasa animal como aglutinante, además de sangre para abrillantar sus pinturas (Martínez, 2002)., Para reforzar esto, la localidad de San Juan Solís, ha sido reconocida por la gran actividad de los tlachiqueros y la extracción del pulque, práctica que se remonta a la fundación del pueblo, lo cual nos dice que las plantas de maguey han estado presentes en la geografía del lugar por un tiempo considerable, siendo plausible el haberlas empleado como aglutinantes., Por su parte el relativamente grueso trazo de las pinturas de El Damie, el cual va de los 2 a los 3 centímetros de grosor, indicaría "el uso de pinceles de la fauna local o fibras vegetales" (Martínez: 2002), aunque como lo menciona Martínez González, se pudieron haber empleado los dedos para remarcar los trazos iniciales, incrementando el grosor de las pinturas, por lo que la posibilidad del uso de pinceles no se ha determinado, aunque se carece de evidencia que sustente este hecho., Cabe añadir otra posibilidad y es que el hecho de que el grosor de las pinturas sean considerable se puede deber a "repintes los cuales señalan el continuo uso de estos sitios como lugar de culto" (Lerma et al., 2014), esto igualmente explicaría la presencia de los anteriormente mencionados, motivos astromorfos en el sitio., Otra hipótesis sobre la preferencia del uso color del blanco por los grupos de filiación Otomí, es la siguiente, donde se sugiere que esto se haya dado, debido "el contraste entre la pintura blanca y el fondo natural, hizo posibles que los motivos resalten y sean observados desde la lejanía" (Lerma et al., 2014)., Un último pero importante dato para añadir concerniente al color blanco, es la gama de motivos pintados por los grupos de filiación Otomí en este color, desde "figuras antropomorfas, formas esteliformes, impresiones de manos, cuadrúpedos y formas estelares" (Martínez, 2002).

En el momento en que definimos algún elemento del Arte o Gráfica Rupestre, "no debemos olvidar el entorno donde se encuentra y que constituye una acción consciente para modificar simbólicamente el paisaje" (Amador, 2018), siendo esta una labor que conlleva una gran dificultad puesto que "el significado de una pintura o grabado cambia según la etnia" (Sánchez, 2000)., El Arte Rupestre con motivos astronómicos, se remonta al momento en que se habitaron los primeros abrigos rocosos, en cuanto ese medio se convirtió en "su principal resguardo y primer punto fijo para la observación de la naturaleza cercana" (Casares, 2017), desde aquella época los seres humanos tuvieron la necesidad de registrar sus observaciones, además es bien sabido que en algunos casos las mismas cuevas o grutas "en sus accesos han sido usadas para la observación celeste (Casares, 2017)., En el presente se entenderá a la Arqueoastronomía de la siguiente manera, como aquella disciplina, la cual se desprende la Astronomía Cultural, que "estudia las evidencias de yacimientos y su relación con la astronomía" (Bonilla et al., 2019)., "Se denominarían motivos planetarios, en semejanza a la función de los modernos instrumentos que existen en michas ciudades para ilustrar al público en general sobre las nociones del firmamento" (Sánchez, 2000)., Por todo lo anterior, las cuevas o abrigos rocosos resultan fascinantes al ser estudiadas, pues han sido las protagonistas y formaron parte de diversos mitos, dentro de la cosmovisión mesoamericana "la cueva participó en la red de significación donde se construyeron los códigos culturales" (Martínez, 2002)., Esto se debió a que a estos espacios se les concediera un carácter sagrado, por lo cual "al constituirse como un espacio ritual se vuelve portadora de diversos significados y simbolismos que varían de acuerdo con el contexto-momento" (Martínez, 2002), ejemplos de esto lo tenemos en las cuevas del Cerro de la Estrella, las cuales dentro de la cosmovisión Mexica, habían sido lugares donde tuvo lugar el nacimiento de Quetzalcóatl, además de ser empleadas en los rituales de los guerreros águila., 
Cubierto lo referente a la realización de las pinturas rupestres y los pigmentos usados, es tiempo de proseguir con el análisis a los motivos y símbolos encontrados en el Damie., Recordando y señalando de forma remarcada, que la interpretación que aquí se les dará a las pinturas puede llegar a ser "una deducción algo forzada y que no se puede aplicar a todas la cuevas o abrigos" (Montes, 2012). Primero se estudiaran los signos cuya forma sea entendible de alguna manera, ya sea porque geométricamente se entiende o se encuentra asociado con algún fenómeno o cuerpo astronómico., Para el análisis de los motivos astronómicos, se usarán los términos desarrollados por el investigador Domingo Sánchez, quien realizó una clasificación sencilla pero entendible, por medio de la separación de las representaciones rupestres en dos grupos de motivos, reconociendo además que esta forma de clasificar a este tipo de manifestaciones se basa en un criterio subjetivo del investigador, quien reconoce que sus conceptos son una aproximación a las formas que este tipo de Arte Rupestre parece representar., Los cuales engloban a una buena parte de los motivos rupestres, que pueden ser denominados como símbolos concernientes a la Arqueoastronomía., El primer grupo de estos trata a los motivos astromorfos: como aquellos que tienen o poseen "la forma de un cuerpo astronómico" (Sánchez, 2000)., Esta agrupación abarca lo siguiente: estrellas, cúmulos estelares, constelaciones, supernovas, galaxias, soles, lunas, eclipses, planetas, conjunciones, cometas y meteoros., $\mathrm{Y}$ como segundo grupo tenemos a las representaciones meteomorfas: entendidas como "cualquier fenómeno o apariencia en la atmósfera (Sánchez, 2000)"., Las formas meteomorfas incluyen a las siguientes representaciones: arcoíris, halos lunares o solares, lluvias intensas, nubes de gran desarrollo, rayos de tormentas, rayos solares, tornados., De acuerdo con la cantidad de ilustraciones que se encuentren en un solo contexto, se podría hablar de un panel con motivos, según Sánchez, es el lugar donde se encuentran en un mismo espacio o juntas, varias representaciones de motivos astromorfos., Aunado con lo anterior se emplearan algunos criterios de la Categorización de las formas radiadas (o en expansión), realizada por la investigadora Luz Helena Ballestas, esta forma de clasificar a los motivos rupestres, abarca "la cruz, el círculo y la espiral” (Ballestas, 2015).,

La forma del círculo ha sido "muy usada desde el chimalli hasta en los monumentales calendarios" (Ballesteros:2015), en cuanto a su uso en el ámbito que nos interesa "algunas representaciones de marcadores incluyen círculos concéntricos, pequeños en cuanto a la proporción del espacio que los contiene" (Ballestas, 2015)., Los cúmulos estelares, así como las estrellas y los planetas pueden manifestarse de la siguiente manera: "agrupaciones o conglomerados de puntos compactos" (Sánchez, 2000)., El sitio del Damie cuenta con un motivo astromorfo, localizado en la primera cueva, en el panel de la izquierda, que presenta los mayores actos de vandalismo., Se observan 11 puntos o figuras circulares perfectamente visibles dispuestos en 5 hileras diagonales, estos no solo tienen la silueta de un círculo sino que toda la forma se encuentra rellenada con pintura., A causa del desgaste no se pudo determinar si en realidad se trataban de 13 de estos motivos, ya que parecían haber dos más, pero estos estaban en una condición muy mala, muy deslavados y poco visibles, eso sin mencionar que los grafitis cubrían buena parte de lo que podría ser uno de estos., Los círculos miden entre 4.4 a 5.1 centímetros de diámetro, todas ellas en color blanco, con una alineación oeste-este, misma que comparte el resto de las pinturas en el sitio., Afirmo que se tratan de motivos astromorfos, debido a que los marcadores astronómicos comparten su misma forma, siendo esta la circular, sumado a lo anterior respetan el criterio de tener una menor proporción con respecto a otros motivos, en este caso un símbolo meteomorfas el astro solar, finalmente en concordancia con la Arqueoastronomía formas como las descritas han sido identificadas como estrellas y de acuerdo con la terminología empleada, se puede tratar de una conjunción de estrellas o una constelación. 


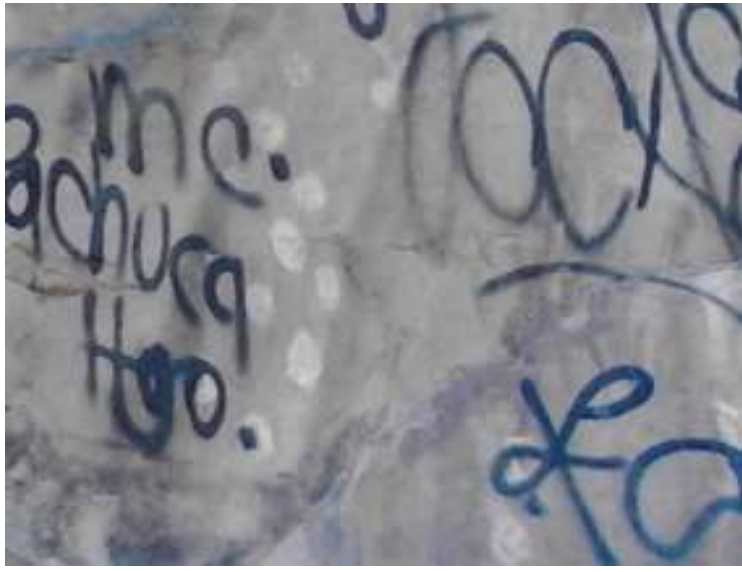

Imagen 3. Posible conjunción de estrellas.

Por su parte, el sol, la luna o las supernovas, "son representadas como discos en 2 dimensiones, siendo el sol un círculo con rayos, mientras que la luna y sus fases o redonda, como un pequeño círculo y sin rayos" (Sánchez, 2000), cabe señalar para reforzar el argumento anterior que el símbolo del "círculo ha sido insistentemente usado para representar al sol, no tanto en su representación esquemática, sino casi siempre rodeado de líneas o triángulos en expansión" (Ballestas, 2015)., Previamente se ha mencionado la existencia de un motivo identificado como astromorfo, identificado como el Sol, contrario con la agrupación de círculos los cuales pueden ser constelaciones, este fue más sencillo de identificar, puesto que comparte muchos aspectos listados al inicio del presente párrafo., El motivo solar en el Damie es uno representado como un círculo en 2 dimensiones, con sus respectivos rayos, teniendo al menos unos 20 de estos, nuevamente el factor de la conservación afecta el análisis, 5 de estos en forma triangular o que terminan en punta, mientras que el resto son líneas rectas, siendo una imagen esquemática perfecta., Como se ha mencionado antes, esta figura es de un tamaño mayor que los círculos descritos anteriormente, puesto que posee un diámetro de 14 centímetros, con un grosor de 2.5 centímetros., Contrario a los círculos, este no se encuentra rellenado con pintura blanca, sin embargo si cuenta con relleno, puesto que dentro de su silueta fueron pintados 8 pequeños puntos circulares, como los anteriores pero de un tamaño menor, igualmente rellenados, que parecieran cubrir todo el interior del Sol, pero debido al desgaste solo se conservan los del lado izquierdo superior de la figura.,

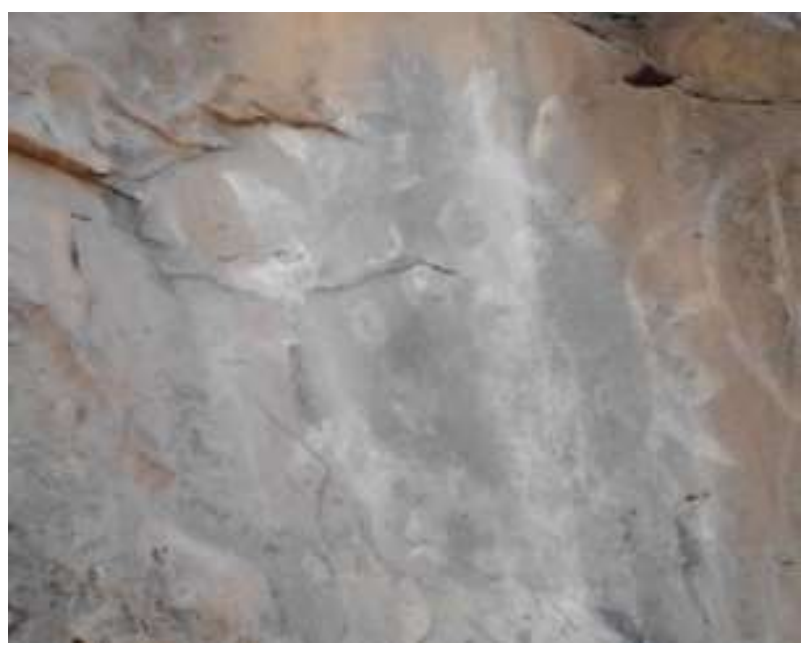

Imagen 4. Motivo del Sol.

Dentro del panel donde se ubica el motivo solar, tenemos otras 3 figuras., La primera de estas viéndolas de izquierda a derecha, parece ser antropomorfa, posee 4 extremidades y una cabeza unidas por una línea recta que cumple con la función de ser un cuerpo., Siguiendo en el mismo sentido tenemos a un línea vertical recta de un tamaño superior a la figura antropomorfa., En tercer lugar, tenemos al más inquietante de este panal, además de tener un grosor superior al motivo solar contando con 3 centímetros, se compone de tres fases., La primera de estas es la base, donde se asemeja a las representaciones de escaleras verticales encontradas en las pinturas rupestres de Alfajayucan, una línea recta atravesada en el medio por otras, pero en el caso del Damie, estas son horizontales y se conectan con una línea recta y gruesa., La segunda fase se trata de un círculo que tiene encima una línea recta horizontal, localizada por encima del motivo de las escaleras y se encuentra paralelo con la línea recta principal., En tercer tenemos que la línea recta a la cual están conectadas las escaleras, en su parte superior se reduce su grosor y cambia de dirección, ya no es recta sino que apunta hacia la izquierda., El motivo que acaba de ser descrito es uno de los más complejos, si no es que el que más trabajo costó comprender al momento de analizar las pinturas, ya que entra en la categoría de motivos amorfos, pero que 
al mismo tiempo tiene componentes geométricos y otros signos similares a otros motivos rupestres estudiados, por lo que en el presente no se pudo dar una interpretación de lo que posiblemente represente., Siguiendo con la secuencia tenemos como 4to motivo al Sol y finalmente a un arco, este fue representado en forma de $D$ volteada al lado contrario que como se escribe, apuntando al sol y se encuentra muy pegado a este motivo, hasta el momento, este resulta ser el único signo que podría tener cierta relación con los usados por los Chichimecas, siendo los anteriores signos, muy similares a los empleados por los grupos de filiación Otomí, en distintas áreas del estado de Hidalgo.

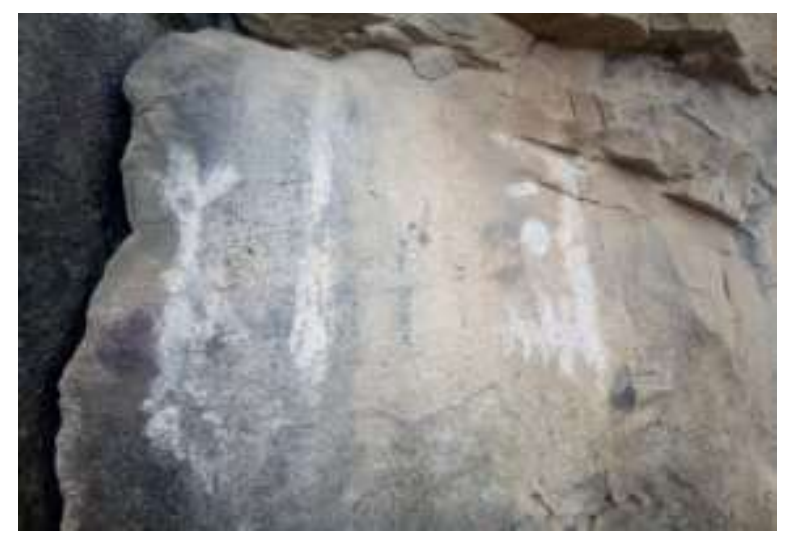

Figura 5. Motivos geométricos, antropomorfos y rectas.

Llega el momento de describir los motivos de la segunda cueva, cuyos motivos tienen un mayor desgaste por los efectos tafonómicos, como el clima o la propia luz solar, que dificultan aún más su interpretación, ya que no se ha determinado la extensión de estos, debido a que en algunos parecen haber partes faltantes., Empecemos con el panel de 3 motivos., El primero en la dirección derechaizquierda, parece ser una media luna, ya que se trata de una línea cóncava hacia abajo, la cual fue vandalizada con los nombres de algunas personas grabados encima de ella, y una línea tallada casi a la mitad de la misma, esta línea fue recubierta con gis.

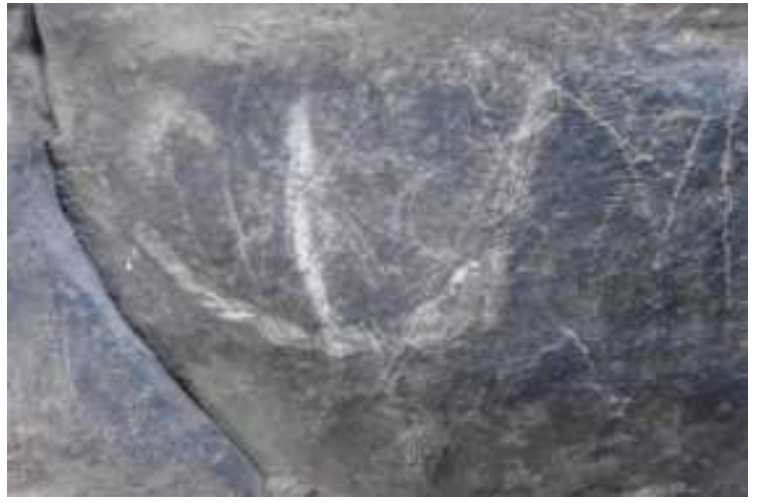

Figura 6. Posible representación de una media Luna.

Para el segundo motivo nuevamente entramos en el campo de la especulación, puesto que a priori resulta ser un motivo amorfo, un círculo donde en el interior de su silueta fueron pintadas líneas rectas que aparentemente se conectan con un segundo círculo, menciono la palabra "aparentemente", porque justo en esa parte hay un desprendimiento de la roca, por lo que solo se perciben las líneas del lado izquierdo y no se ha determinado si lo que se observa de ese supuesto segundo círculo, sea producto del vandalismo, desgaste u otros factores.

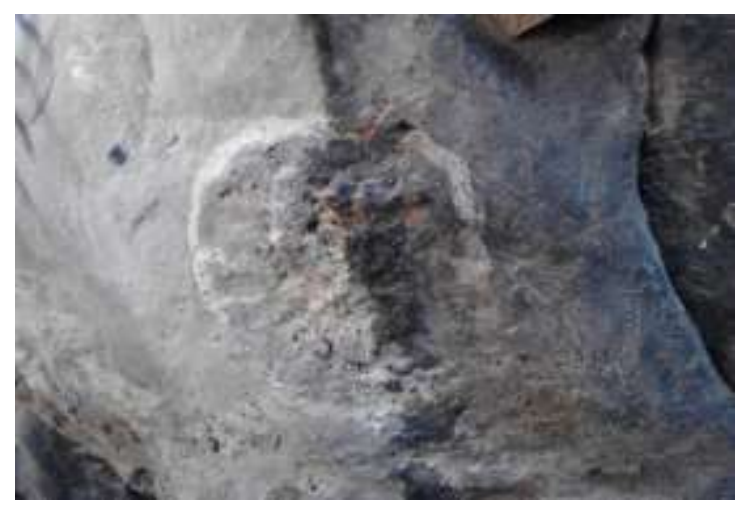

Figura 7. Motivo circular indeterminado.

Encima de estos motivos se localiza el tercero tres círculos, pueden tratarse de motivos astromorfos, ya que son similares a los descritos anteriormente, teniendo medidas semejantes, pero estando a una altura mucho mayor que el resto, ya que superan los 3 metros de alto., 


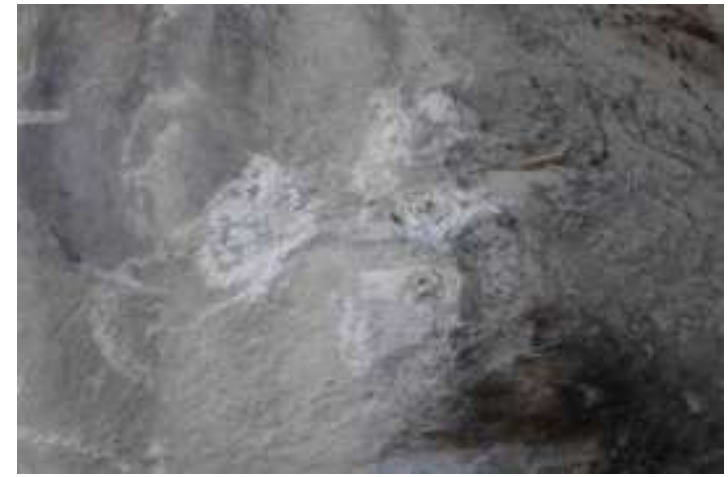

Figura 8. Posible motivo astromorfo.

El cuarto motivo pintado en uno de los techos bajos de la cueva a la misma altura que la luna y el círculo., Se trata de otra figura circular, un círculo con un segundo círculo en su interior y en el centro de este un punto., Este motivo es de los más desgastados ya que partes del contorno del primer círculo han desaparecido y otros fragmentos de la pintura fueron desprendidos.,

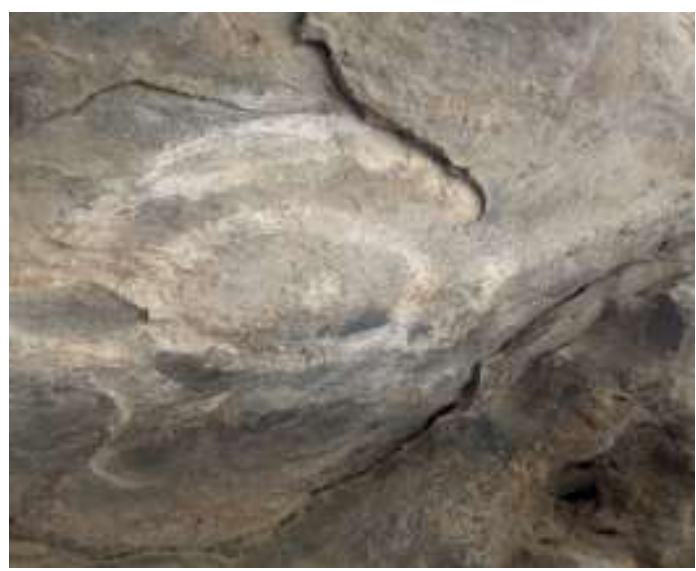

Figura 9. Figura circular.

Después tenemos a una quinta pintura, localizada por encima de los tres círculo, misma que no se ha determinado si se trata de una obra reciente o de otra pintura vandalizada., Esto se debe a que se aprovechó el perfil de la pared rocosa y dos desprendimientos para pintar lo que a primera vista se trata de una cabeza con ojos, nariz y boca., Para la nariz y la boca se abrían aprovechado los desprendimientos, teniendo un color blanco que desentona con el resto y que se ha conservado sorprendentemente muy bien., No resulta difícil pensar que esta se trate de una creación reciente de algún curioso que haya querido dejar su huella, ya que en otras oquedades de las laderas rocosas han sido usadas para pintar otras "caritas" como las llaman los pobladores, uno de mis guías afirmó ser el autor de una de estas "caritas", la cual pintó hace más de 20 años., Esto me dejo la duda de que todas las pinturas hayan sido pintadas en los últimos años., Sin embargo, esta misma que se disipó por una gran cantidad de razones, como el ser informado que las pinturas rupestres para cuando se empezaron a pintar las "caritas" ya existían, otros pobladores de mayor edad igualmente afirman que estas pinturas existen desde que se venían a pastorear hace ya unos 50 años., Estos testimonios junto a los materiales arqueológicos hallados cerámicos como líticos, los motivos analizados en la primera cueva los cuales presentan un parecido bastante grandes con otros sitios con gráfica rupestre en Hidalgo, el área donde se localizan, la presencia de montículos/sitios arqueológicos cercanos, y el sitio del Huarache (las cuales no tienen ningún indicio de vandalismo ni "caritas" debido a su difícil acceso contrario al Damie que está a lado de un camino transitado por pastores, autos y otros pobladores) terminaron de disipar mis dudas sobre su autenticidad, de todos los motivos menos este último mencionado., Aunque no estaría demás en el futuro o cuando los medios lo permitan, el realizar un fechamiento sobre estas pinturas para terminar con todas las dudas respecto a su autenticidad.,

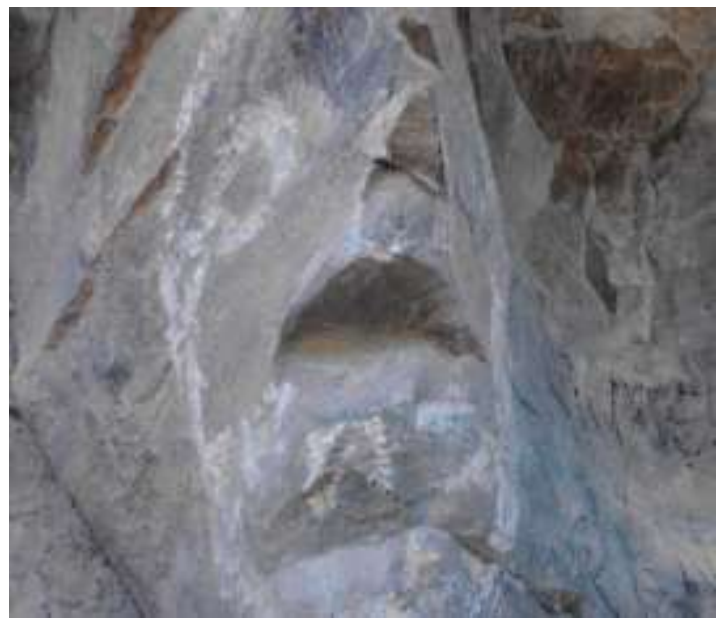

Figura 9. Posible representación de una "carita". 


\section{CONCLUSIONES}

Tenemos otro indicio que nos podría acercar al grupo que realizo estas pinturas, en párrafos anteriores se ha mencionado la posibilidad de que estos sean de filiación Otomí o Chichimeca emparentados con estos, debido a la región donde se encuentra el Damie, la cronología tentativa de ellas o el color de las mismas, sin embargo, fuera de los aspectos arqueoastronómicos, los motivos plasmados, son igualmente una gran pieza de información para tratar la problemática de sus autores. Tanto los otomíes del mezquital como los chichimecas, "distribuían sus pinturas a lo largo de barrancas y arroyos" (Lorenzo y Vergara, 2015)., Se hace hincapié, que estos conjuntos de pinturas rupestres, los cuales comparten algunas de las siguientes características, como la ubicación en barrancas que lindan con cuerpos de agua, los motivos plasmados en ellas y el color usado, "podrían ser consideradas como de la misma familia" (Martínez, 2002), siendo esta la familia de Pinturas Rupestres del Estado de Hidalgo, donde se incluyen a las pinturas del Damie, como se ha venido mencionando., Se puede descartar tentativamente que sus autores sean de filiación Chichimeca debido a que no se encuentran representaciones que "rememoren el proceso de migración de Xólotl, como escudos, escenas de la cacería del venado o el motivo del caracol emplumado" (Lorenzo y Vergara, 2015)., Motivos muy presentes en los sitios identificados con autores de esta filiación., Lo único que podría parecer a estos motivos chichimecas sería el arco, pero esta posibilidad ya ha sido tratada anteriormente $y$ se han dado otras propuestas de lo que puede significar, por lo que es muy reducida la evidencia que los relaciones con los chichimecas., Reforzando la hipótesis donde los realizadores de estos motivos fueron miembros de algún grupo con filiación otomí, tenemos al motivo del sol "usado para dar un orden cronológico a las secuencias de imágenes presentadas" (Martínez, 2002)., El tener la presencia del motivo del astro lunar, resulta de primordial importancia, ya que este es un símbolo altamente asociado con los grupos de filiación otomí, debido a que ellos consideran "que el astro lunar nació en una cueva" (Martínez, 2002), por ello su presencia en una gran cantidad de abrigos rocosos en las regiones ocupadas por este grupo., Esto sin mencionar que las dos principales deidades de los grupos otomíes, eran justamente el Sol y la Luna, por lo que el tener ambos motivos, en el característico color blanco que distingue a este grupo, es buen indicio., En cuanto al significado de las pinturas debemos tomar en cuenta que es "el contexto condiciona la elaboración del arte" (Montes, 2012)., Por ello lo que observamos en el Damie no puede ser entendido, si desconocemos al grupo quien las elaboró, de acuerdo con mi teoría de que estas habrían sido realizadas por un grupo de filiación ñhañhu u otomí, estaríamos ante una representación de fenómenos astronómicos, posiblemente usados en alguna ceremonia o ritual, o posiblemente un marcador de algún fenómeno astronómico, o un marcador de territorio., O tal vez, aunque no hay mucha evidencia o estudios que lo sustenten, se trate de algún calendario $o$ anotaciones que permitieran conocer o rememorar fechas, sucesos 0 fiestas importantes, e igualmente está la hipótesis de que las pinturas hubieran sido realizadas tras haber atestiguado algún fenómeno en el cielo, mismo que fue tan anómalo, que les hizo querer representarlo para poder conservar el registro de aquel suceso., Sin embargo y cabe añadir que estas son solo simples interpretaciones y conjeturas, lo cierto es que contamos con representaciones de motivos astromorfos y meteoformos, así como una figura antropomorfa, los cuales interactúan entre sí, junto con otros más que no han sido identificados del todo, pero que esperamos hacerlo en el futuro., Estos comparten el mismo espacio y se han mantenido por varios siglos como testimonios vivientes de la gente que habitó la zona en otro momento, tiempo y época. Pero cuando menos, se cuentan con elementos suficientes como para poder al menos de forma tentativa, clasificar estos motivos, dentro de la Familia de Pinturas Rupestres del Estado de Hidalgo, relacionando al Damie con los otomíes o algún grupo con filiación ñhañhu, más que con los chichimecas, por la evidencia mostrada hasta el momento. 


\section{Referencias}

[1] Amador Bech, J. (2018). El Arte Rupestre como Medio de Comunicación. Observaciones de Método sobre su Interpretación. www.Researchgate.net/publication/328492033.

[2] Ballestas, L. (2015). Las Representaciones Implícitas en las formas esquemáticas Prehispánicas. Un enfoque comparativo de la cultura material de México y Colombia. En Estancia Posdoctoral Universidad Autónoma de México. Ciudad de México: UNAM.

[3] Berro, F. (2006). Arte Rupestre y Paisaje Simbólico Mesoamericano en el Norte de Durango. En Anales del Instituto de Investigaciones Estéticas (págs. 135-181). Ciudad de México: UNAM.

[4] Berro, F. (2006). Arte Rupestre y Paisaje Simbólico Mesoamericano en el Norte de Durango. En Anales del Instituto de Investigaciones Estéticas (págs. 135-181). Ciudad de México: UNAM.

[5] Bonilla, J., Godoy, O. y Sarmiento, E. (2019) La Arqueoastronomía, una alternativa de enseñanza de la Astronomía Precolombina en el contexto Universitario. En Revista Científica de la Universidad Distrital Francisco José de Caldas (págs. 234-243). Bogotá Distrito de Colombia: Centro de Investigación y Desarrollo Científico de la Universidad Distrital Francisco José de Caldas.

[6] Bonilla, J., Godoy, O. y Sarmiento, E. (2019) La Arqueoastronomía, una alternativa de enseñanza de la Astronomía Precolombina en el contexto Universitario. En Revista Científica de la Universidad Distrital Francisco José de Caldas (págs. 234-243). Bogotá Distrito de Colombia: Centro de Investigación y Desarrollo Científico de la Universidad Distrital Francisco José de Caldas.

[7] Casares Contreras, O. Del cielo al inframundo: observatorios astronómicos subterráneos de Mesoamérica. En Temas Antropológicos, Revista Científica de Investigaciones Regionales (págs. 105-122). Mérida: UAY.

[8] Cruz Berrocal, M. (2004). Paisaje y Arte Rupestre: Ensayo de contextualización Arqueológico y Geográfico de la Pintura Levantina. Madrid: Universidad Complutense de Madrid.

[9] Enciclopedia de Municipios de México, "Estado de Hidalgo. Alfajayucan", en línea [http://intranet.ehidalgo.gob.mx/enciclomuni/municipios/13006a.htm], consultada: 2021-04-22.

[10] [Enciclopedia de Municipios de México, "Estado de Hidalgo. San Agustín Tlaxiaca", en línea [http://intranet.ehidalgo.gob.mx/enciclomuni/municipios/13052a.htm], consultada: 2021-01-31.

[11] Enciclopedia de Municipios de México, "Estado de Hidalgo. San Bartolo Tutotepec", en línea [http://intranet.ehidalgo.gob.mx/enciclomuni/municipios/13053a.htm], consultada: 2021-04-22.

[12] Galicia, A. y Sánchez, S. (2004). Introducción. En Hidalgo, Diseño e Iconografía Geometrías de la Imaginación (págs. 11-16). México:
Dirección General de Culturas Populares de CONACULTA y Consejo Estatal para la Cultura y las Artes de Hidalgo.

[13] Hidalgo, Centro INAH, en línea [https://www.centrohidalgo.inah.gob.mx/], consultada: 2021-01-31.

[14] Lerma, F., Hernández, N., y Peña, D. (2014). Un Acercamiento a la Estética del Arte Rupestre del Valle del Mezquital México (págs. 5370). En Boletín del Museo Chileno de Arte Precolombino. Santiago de Chile: MCAP.

[15] Lorenzo, C., Vergara, A. (2015). Las Pinturas Rupestres de El Cajón, Huichapan. En MAGOTZI Boletín Científico De Artes Del IA. Pachuca de Soto Hidalgo: UAEH.

[16] Martínez González, R. (2002). La Cueva del Río San Jerónimo: análisis e interpretación de su Arte Rupestre (págs. 0-30). En Revista Cuicuilco. Ciudad de México: ENAH.

[17] Montes Gutiérrez, R. (2021) Teorías Interpretativas del arte rupestre (págs. 5-22). En Tiempo y Sociedad Revista de Historia y Humanidades). España, Oppidum Noega.

[18] Norma De Escritura De La Lengua HÑAHÑU (OTOMI). De los Estados de Guanajuato, Hidalgo, Estado de México, Puebla, Querétaro, Tlaxcala, Michoacán y Veracruz. (2014). Ciudad de México: Secretaría de Educación Pública, Instituto Nacional de Lenguas Indígenas.

[19] Pinturas Rupestres y Petrograbados, en línea [http://cultura.hidalgo.gob.mx/5901/], consultada: 2021-01-17.

[20] Sánchez, D. (2000). La Arqueoastronomía en el Arte Rupestre: Una Propuesta Metodológica. equiponaya.com.ar/congreso2000/ponencias/Domingo_Sanchez.htm

[21] Schonleber, I. y Lira, J. (2007). La Minería de la Obsidiana Actual y Prehispánica en la Sierra de las Navajas, Hidalgo.Tesis de Licenciatura en Arqueología. Ciudad de México: ENAH.

[22] Zona Arqueológica Cerro de la Estrella, en línea [https://www.inah.gob.mx/zonas/27-zona-arqueologica-cerro-de-laestrella], consultada: 2021-01-31.

[23] Zona Arqueológica Pañhu, en línea [https://www.inah.gob.mx/zonas/57-zona-arqueologica-panhu], consultada: 2021-04-23.

[24] Zona Arqueológica Tepeapulco o Xihuingo, en línea [https://www.inah.gob.mx/zonas/82-zona-arqueologica-tepeapulco-oxihuingo], consultada: 2021-04-23.

[25] Zona Arqueológica Tula, en línea [https://www.inah.gob.mx/zonas/80zona-arqueologica-y-museo-de-sitio-de-tula], consultada: 2021-04-23. 